\title{
Erratum: Studies on the Interaction Between Oxygen and Lead Chalcogenide Surfaces
}

\author{
J. Gałat, ${ }^{*}$ J. Haber, ${ }^{*}$ J. Nowotny, ${ }^{*}$ and J. B. Wagner, Jr. $\dagger$
}

In this paper [Oxid. Met.9, 497-506 (1975)] on page 502, the keys defining curves 1 and 2 of Fig. 4 were inadvertently switched.

Thus, the caption to Fig. 4 should read: "Kinetics of the CPD changes for $\mathrm{PbTe}-$ in oxygen at $350^{\circ} \mathrm{C}$ (curve 2) and at $20^{\circ} \mathrm{C}$ after outgassing at $350^{\circ} \mathrm{C}$ (curve 1)."

Similarly, the sentence beginning on line 4 , page 502, should read: "Figure 4 shows the work function changes accompanying oxygen adsorption on $\mathrm{PbTe}$ measured at $350^{\circ} \mathrm{C}$ vs time (see curve 2 ) and at $20^{\circ} \mathrm{C}$ (see curve 1) after its outgassing in vacuo at $350^{\circ} \mathrm{C} . "$

*Research Laboratories of Catalysis and Surface Chemistry, Polish Academy of Sciences, Krakow, Poland.

$\dagger$ Department of Materials Science and Materials Research Center, The Technological Institute, Northwestern University, Evanston, Illinois. 